\title{
Chromate-free passivation of aluminum alloys for paint repair technologies
}

\author{
Yu. P. Avdeev, ${ }^{1}$ V. A. Karpov, ${ }^{1}$ L. B.Maksaeva ${ }^{2}$ and M. A. Petrunin ${ }^{2}$
}

${ }^{1}$ A.N.Severtsev Institute of ecology and evolution problems, Russian Academy of Sciences, Leninskii pr. 33, Moscow, 119071 Russian Federation

${ }^{2}$ A. N. Frumkin Institute of Physical Chemistry and Electrochemistry, Russian Academy of Sciences, Leninskii pr. 31, Moscow, 119071 Russian Federation

E-mail:maxim@ipc.rssi.ru

\begin{abstract}
A comparative evaluation of the protective properties of chromate-free passivating formulations offered as an alternative to the widely used method for passivation of aluminum surfaces by $\mathrm{Cr}(\mathrm{VI})$ compounds has been carried out. It has been shown that the protective properties of the compounds tested in the system with the EP-0215 primer are nearly not inferior to the formulations based on hexa- and trivalent chromium.
\end{abstract}

Key words: aluminum alloys, passivating formulations, local chemical oxidation, hexavalent chromium, corrosion tests, paint coatings.

Received: June 1, 2014.

doi: $10.17675 / 2305-6894-2014-3-3-198-203$

\section{Introduction}

Analysis of domestic and foreign scientific and technical information concerning the evaluation of the efficiency of equipment protection from corrosion shows that the widely used method of additional surface treatment of aluminum alloys before painting with appropriate paint systems, "local chemical oxidation" with formulations based on hexavalent chromium compounds, has a considerable drawback in terms of its failure to comply with contemporary ecological requirements. Hexavalent chromium in these formulations is an ecologically harmful element that is highly undesirable today and will be ultimately prohibited at all [1,2]. In view of this, the search for, and practical implementation of, more efficient and ecologically acceptable means for additional surface treatment during repair of equipment in day-to-day operation and during plant painting activities is rather an important scientific and engineering task of current interest.

These days, a number of developers, both in Russia and abroad, offer alternative passivating formulations without hexavalent chromium for additional treatment of metal surfaces. For example, the German company SurTec [3] offers a number of formulations based on trivalent chromium that ensure acceptable protective properties of films formed on aluminum alloy surfaces. In this case, the thickness of conversion coatings is about 20$100 \mathrm{~nm}$ and the optimum temperature of the working solutions is $30-40^{\circ} \mathrm{C}$. Henkel (Germany) offers the Alodine 871 formulation based on trivalent chromium for this 
purpose [4]. The formulation creates a thin conversion film on the metal surface at ambient environmental conditions and does not require washing with water before the paint application. Russian company "NPP Tekhnobior" [5] offers passivating formulations based on phosphoric acid, surfactants, complexons, and corrosion inhibitors for additional treatment, in particular, of aluminum alloys, before application of appropriate paint materials. When aluminum is prepared for painting, this formulation allows two process operations, namely, degreasing and etching, to be combined into one stage. Alufinish $\mathrm{GmbH} \& \mathrm{Co} . \mathrm{KG}$ (Germany) also offers a wide variety of products for the preparation of metal surfaces for finish painting [6], including the so-called no-rinse chromating technology during which toxic $\mathrm{Cr}(\mathrm{VI})$ is converted to $\mathrm{Cr}(\mathrm{III})$. While noting the benefits of the proposed technologies in terms of ecological requirements, we should mention that these technologies are more suitable for large-scale production. As concerns the technologies for repair and restoration of locally damaged protective coatings on equipment under service conditions, it would be desirable to have "green" technologies for these purposes, i.e., technologies that can be implemented without the need for powerconsuming process equipment, at ordinary air temperatures, and with short-term exposures, do not involve multiple stages, and do not require high personnel skills. Based on the above, in this study we used accelerated corrosion testing for comparative estimation of protective properties of formulations for additional surface treatment. We estimated the following products: Alodine 871 (Henkel) based on trivalent chromium, "TMSDP" chromate-free product from NPO "Tekhnobior" (Russia), and two chromate-free aqueous passivating formulations based on organosilanes and molybdates developed at IFKhE (Institute of Physical Chemistry and Electrochemistry) and IPEE (Institute of Ecology and Evolution), respectively, both of the Russian Academy of Sciences, which can be recommended in repair technologies for restoration of paint coatings on structural aluminum alloys. An $\mathrm{CrO}_{3}: \mathrm{KHF}_{2}: \mathrm{K}_{3}\left[\mathrm{Fe}(\mathrm{CN})_{6}\right]$ aqueous solution used in repair practice [7] was used as the reference formulation.

\section{Test procedure}

\section{Specimen preparation}

Metal plates from aluminum alloys of grades 1163 , D16 and V95, size $150 \times 70 \times 1.5 \mathrm{~mm}$, were used as the specimens for application of the corresponding formulations. The specimens were pretreated by degreasing and etching. After that, the formulations were applied by slight rubbing of the surfaces for 1-2 min with cotton wads. The passivating formulations were applied in two layers with a 15-20 min interval at room temperature of the air and a relative humidity of $50-70 \%$. The specimens prepared in this manner were then coated with two layers of EP-0215 cold drying primer. The total primer thickness on the specimens was $40-60 \mu \mathrm{m}$. 


\section{Parameters estimated}

The efficiency of corrosion protection of aluminum specimens with the coatings studied was estimated using the following indicators:

- salt spray resistance;

- thermal stability;

- resistance against alternating temperature loads;

- water resistance;

- resistance against organic solvents;

- resistance against antifreezes;

- resistance against aviation fuel.

\section{Testing}

For better understanding of the subsequent matter, we assigned the following sequence numbers to the formulations studied:

No. $1-\mathrm{a} \mathrm{CrO}_{3}: \mathrm{KHF}_{2}: \mathrm{K}_{3}\left[\mathrm{Fe}(\mathrm{CN})_{6}\right]$ formulation;

No. 2 - a formulation based on organosilanes;

No. 3 - a formulation based on molybdates;

No. 4 - the "TMSDP" formulation;

No. 5 - the "Alodine 871 " formulation.

The resistance of the formulations against liquid media was estimated in accordance with GOST (State standard) 9.403 [8] and ISO 2812-1 [9]. The following liquid media were used: distilled water, an isooctane: toluene mixture (75:25), TS-1 aviation fuel [10], NGZh 5u hydraulic fluid [11], and OCTAPLO EG de-icing fluid manufactured by OJSC "AVIAFLYUID" (Russia). The specimens were immersed vertically by $2 / 3$ of the specimen height in glass beakers containing a corresponding test medium and kept at $20 \pm 2^{\circ} \mathrm{C}$ for 14 days in the case of water, 7 days for aviation fuel or de-icing fluid, or $2 \mathrm{~h}$ for organic solvents. The changes in the coating protective properties were estimated according to GOST 9.407 [12], those of adhesion - according to GOST 15140 [13].

Tests in neutral salt spray were carried out according to GOST 9.308 [14] at $35 \pm 1{ }^{\circ} \mathrm{C}$, the salt solution concentration was $5 \%$, and the salt spray particle size was $1-10 \mu \mathrm{m}$. The test duration was $1500 \mathrm{~h}$.

The resistance to alternating temperature load was determined according to Boeing standard BMS 10-72N [15]. The test cycle involved heating the specimens for $25 \mathrm{~min}$ at $71^{\circ} \mathrm{C}$ followed by exposure for $5 \mathrm{~min}$ in a freezing chamber at $-53^{\circ} \mathrm{C}$. The number of cycles was 24 .

Thermal stability tests were carried out according to AITM 2-0014 standard [16] in a thermal chamber at $150 \pm 2^{\circ} \mathrm{C}$ for $100 \mathrm{~h}$. The condition of the specimens was estimated according to GOST 9.407-84. 


\section{Test results}

The results of accelerated corrosion tests for specimens of structural materials with the formulations of interest are given in Table 1. To facilitate the understanding of the results, the latter are grouped by a key attribute, in this case, the substrate material. The formulation based on hexavalent chromium was used as the reference system in all cases. The test results are given in Table 1 as a fraction, where the protective effect in points according to GOST 9.407 is shown as the numerator and the adhesion after exposure to the corresponding factor, in points according to GOST 15140, is shown as the denominator.

Table 1. Results of accelerated corrosion tests.

\begin{tabular}{|c|c|c|c|c|c|c|}
\hline $\begin{array}{c}\text { Formulation } \\
\text { No. }\end{array}$ & Substrate & $\begin{array}{l}\text { Water } \\
\text { resistance }\end{array}$ & $\begin{array}{l}\text { Resistance } \\
\text { to process } \\
\text { fluids }\end{array}$ & $\begin{array}{l}\text { Salt spray } \\
\text { resistance }\end{array}$ & $\begin{array}{l}\text { Thermal } \\
\text { stability }\end{array}$ & $\begin{array}{l}\text { Resistance to } \\
\text { alternating } \\
\text { temperatures }\end{array}$ \\
\hline \multirow{3}{*}{1} & 1163 & $1 / 1$ & $1 / 1$ & $1 / 1$ & $1 / 1$ & $1 / 1$ \\
\hline & D16 & $1 / 1$ & $1 / 1$ & $1 / 1$ & $1 / 1$ & $1 / 1$ \\
\hline & V95 & $1 / 1$ & $1 / 1$ & $1 / 1$ & $1 / 1$ & $1 / 1$ \\
\hline \multirow{3}{*}{2} & 1163 & $\mathbf{P} 2 / 1$ & $1 / 1$ & $1 / 1$ & $1 / 1$ & $1 / 1$ \\
\hline & D16 & $1 / 1$ & $1 / 1$ & $1 / 1$ & $1 / 1$ & $1 / 1$ \\
\hline & V95 & $1 / 1$ & $1 / 1$ & $1 / 1$ & $1 / 3$ & $1 / 1$ \\
\hline \multirow{3}{*}{3} & 1163 & $\mathbf{P} 3 / 3$ & $1 / 1$ & $1 / 2$ & $1 / 2$ & $1 / 2$ \\
\hline & D16 & $1 / 4$ & $1 / 1$ & $1 / 1$ & $1 / 1$ & $1 / 1$ \\
\hline & V95 & $1 / 1$ & $1 / 1$ & $1 / 1$ & $1 / 1$ & $1 / 1$ \\
\hline \multirow{3}{*}{4} & 1163 & $\mathrm{P} 2 / 1$ & $1 / 1$ & $1 / 1$ & $1 / 1$ & $1 / 1$ \\
\hline & D16 & $1 / 1$ & $1 / 1$ & $1 / 1$ & $1 / 1$ & $1 / 1$ \\
\hline & V95 & $1 / 1$ & $1 / 1$ & $1 / 1$ & $1 / 1$ & $1 / 1$ \\
\hline \multirow{3}{*}{5} & 1163 & $1 / 1$ & $1 / 1$ & $1 / 1$ & $1 / 1$ & $1 / 1$ \\
\hline & D16 & $1 / 1$ & $1 / 1$ & $1 / 1$ & $1 / 1$ & $1 / 1$ \\
\hline & V95 & $1 / 1$ & $1 / 1$ & $1 / 2$ & $1 / 1$ & $1 / 1$ \\
\hline
\end{tabular}

One can see from these data that the formulations for additional treatment of aluminum alloy surface that we have tested provide rather efficient protective coatings. The generalized indicator of protective properties of the systems tested on all the substrates mostly equals 1 point. It is only in water resistance experiments with coatings on substrates from aluminum alloy 1163 and formulations No. 2, 3, and 4 that blistering was observed, which decreased the generalized indicator of protective properties to the 2-3 points level. Furthermore, in tests with formulation No. 3, the adhesion indicator was found to decrease by 1 point at some other loads. 
Thus, the "protective efficiency rating" of the formulations studied toward the effect of various process liquids, water, and thermal loads can be arranged in the following series, in decreasing order: No. $1 \rightarrow$ No. $5 \rightarrow$ No. $4 \rightarrow$ No. $2 \rightarrow$ No. 3 , as shown graphically in Figure 1.

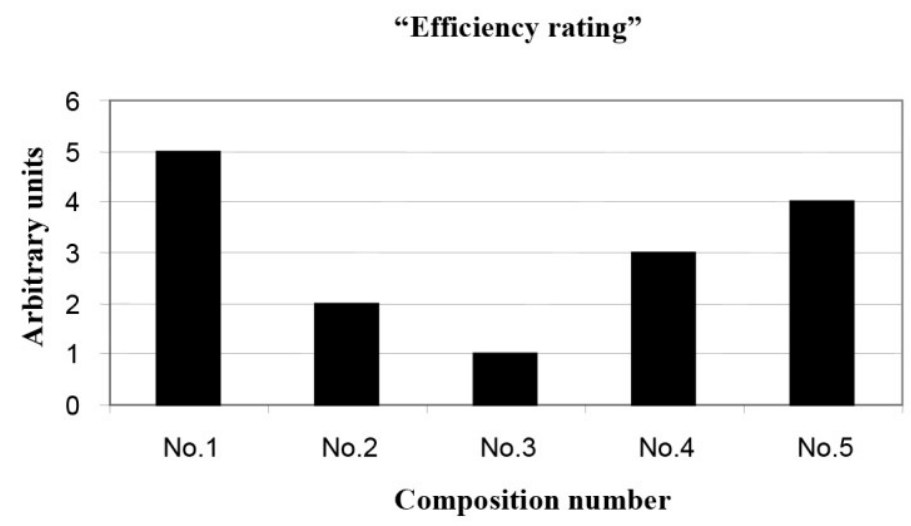

Figure 1. Efficiency rating for the compositions tested.

\section{Conclusions}

The formulations for additional treatment of aluminum alloy surfaces that we tested show rather high protective properties and can be recommended for practical application as alternatives to passivating formulations containing hexavalent chromium.

\section{References}

1. Directive 2002/95/EC of the European Parliament and of the Council.

2. Directive 2011/65/EU of the European Parliament and of the Council.

3. SurTec650. SurTecDeutschland GmbH. [Electronic resource].

URL: http://www.surtec.com/Kataloge/Aluminium eng.html (application date: 10.04.2008).

4. Alodine 871, Technical Process Bulletin No. 234114, Henkel, 2006.

5. TU (Technical Specification) 2383-002-56478541-01, Moscow, OOO NPP "Tekhnobior", 2001 (in Russian).

6. Pretreatment of aluminium prior to coating, Alufinish GmbH \& Co. KG. [Electronic resource]. URL: http://www.alufinish.com/ (Electronic resource: 09.04.2008).

7. Manual on corrosion protection of YaK-40 aircraft in operation (RE-4), Moscow, Industrial publication of NTs PLG VS GosNII GA, 2000 (in Russian).

8. Unified system of corrosion and ageing protection. Paint coatings. Methods for determination of resistance to static exposure to liquids, GOST (State Standard) 9.40380 (in Russian).

9. Paints and varnishes. Determination of resistance to liquids, Part 1: Immersion in liquids other than water, ISO 2812-1:2007.

10. Fuels for jet engines, GOST (State Standard) 10227-86 (in Russian). 
11. Process fluid NGZh-5U, TU (Technical Specification) 38.401-58-57-93 (in Russian).

12. Paint coatings. A method for outward appearance estimation, GOST (State Standard) 9.407-84 (in Russian).

13. Paint materials. Adhesion determination methods, GOST (State Standard) 15140-78 (in Russian).

14. Unified system of corrosion and ageing protection. Metal and non-metal inorganic coatings. Accelerated corrosion test methods, GOST (State Standard) 9.308-85 (in Russian).

15. BMS 10-72N Exterior Decorative Paint System, revised 27-FEB-1997.

16. Determination of the effect of thermal exposure, Test Method, AITM2-0014. 